九州大学学術情報リポジトリ

Kyushu University Institutional Repository

\title{
Improvement of Electric Conductivity of Non- graphitizable Carbon Material via Breaking-down and Merging of the Microdomains
}

Kim, Doo-Won

Interdisciplinary Graduate School of Engineering Sciences, Kyushu University

Kil, Hyun-Sig

Interdisciplinary Graduate School of Engineering Sciences, Kyushu University

Nakabayashi, Koj i

Interdisciplinary Graduate School of Engineering Science, Kyushu University | Institute for Materials Chemistry and Engineering, Kyushu University

Yoon, Seong-Ho

Interdisciplinary Graduate School of Engineering Science, Kyushu University | Institute for Materials Chemistry and Engineering, Kyushu University

他

https://doi.org/10.5109/1808307

出版情報: Evergreen. 4 (1)，pp. 16-20，2017-03. Green Asia Education Center バージョン：

権利関係 : 


\title{
Improvement of Electric Conductivity of Non-graphitizable Carbon Material via Breaking-down and Merging of the Microdomains
}

\author{
Doo-Won Kim ${ }^{1}$, Hyun-Sig Kil ${ }^{1}$, Koji Nakabayashi ${ }^{1,2}$, Seong-Ho Yoon ${ }^{1,2, *}$, \\ Jin Miyawaki ${ }^{1,2, *}$ \\ ${ }^{1}$ Interdisciplinary Graduate School of Engineering Sciences, Kyushu University, 6-1 Kasuga-koen, Kasuga, Fukuoka, \\ 816-8580, Japan. \\ ${ }^{2}$ Institute for Materials Chemistry and Engineering, Kyushu University, 6-1 Kasuga-koen, Kasuga, Fukuoka \\ 816-8580, Japan.
}

*Authors to whom correspondence should be addressed,

E-mail: yoon@cm.kyushu-u.ac.jp (S.Y.), miyawaki@cm.kyushu-u.ac.jp (J.M.)

(Received December 24, 2016; accepted January 11, 2017).

\begin{abstract}
Highly graphitized carbon with high electric conductivity was successfully prepared from non-graphitizable carbon (NGC) via breaking-down and merging of boundaries of microdomains through the potassium hydroxide $(\mathrm{KOH})$ treatment and subsequent graphitization. After the graphitization at $2800^{\circ} \mathrm{C}$, the $\mathrm{KOH}$-treated sample showed modified domains having merged boundaries between the microdomains which could be observed in graphitizable carbon (GC). Such a domain-modified carbon showed less than half electric resistivity of graphitized NGC, indicating that macroscopic properties, such as electric conductivity, of carbon materials can be improved via the modification of nanometer-scale microdomain and domain structures.
\end{abstract}

Keywords: Electric conductivity, Graphitizable carbon, Microdomain, Non-graphitizable carbon

\section{Introduction}

Electric conductivity is one of the most important physical properties for effective applications of carbon materials ${ }^{1)}$. Such a property has been recognized to be affected by the composed molecules and their orientation of carbon material. Carbon material is commonly classified into graphitizable and non-graphitizable carbons (GC and NGC, respectively), according to the degree of graphitization after heat treatment above $2400^{\circ} \mathrm{C}$ ("graphitization") $)^{2-4}$. The graphitized GC is composed of the large stackings of well-developed oriented hexagonal carbon layers (graphenes), such as single-crystal graphite, which has usually high electric and thermal conductivities ${ }^{5,6)}$. In contrast to GC, NGC is usually difficult to convert to highly graphitized carbon, even after heat treatment above the graphitization temperature because of its randomly oriented small graphene stackings ${ }^{7-10)}$.

Franklin has reported a relationship between the molecular structure of such carbon precursors and their graphitization behaviors, based on X-ray diffraction (XRD) analyses of various carbonaceous materials ${ }^{2}$. In the Franklin model, GCs show an oriented molecular structure (parallel and regular), whereas the molecular orientation of NGCs is essentially random. Such differences of the graphene stacking and orientation have been considered to be key reasons for differences of the electric and thermal conductivities.

In 1996, our group has newly proposed a novel structural model of carbon materials based on microdomain and domain structural units that could restrict the magnitude of graphene molecular crystalline development in the graphitized GCs ${ }^{11)}$. For the analysis of mesophase pitch based carbon fiber, we have proposed that domains, composed of microdomains (a quasi-aligned molecular assembly unit), in the mesophase pitch were closely packed, being aligned but incompletely connected; this configuration restricted an increase of the graphitic degree after the graphitization treatment ${ }^{11)}$. Later, we have improved the domain-based structural analysis of carbon material into a hierarchical domain structural analysis ${ }^{12}$. The hierarchical domain structural analysis of carbon material can be explained as the serial formation of carbon structures from molecules (e.g., a hexagonal carbon layer), molecular assemblies (e.g., stacked units), microdomains (an assembly of stacked units), domains (an assembly of microdomains), and bulk (an assembly of domains). Based on this hierarchical domain structural analysis, we defined a GC as being composed of domains that have partially merged microdomains, whereas a NGC is composed of domains that have few or no merged (almost independent) microdomains. Thus, in a hierarchical 
domain structural analysis, GCs have larger domain sizes, of 20-70 nm, composed of partially merged microdomains, whereas NGCs have similar or slightly larger domains with microdomains of 5-15 nm. From this hierarchical analysis, we can be sure that the structural conversion of NGC to GC, that is, the successful conversion of NGC domain into GC one, enables a preparation of the well-developed graphitic carbon with high electric conductivity even from the NGC precursors.

Highly graphitized carbons are applicable to various fields where high electric and thermal conductivities, and high corrosion resistance are required. However, GC precursors, such as mesophase pitch, needle coke, and anisotropic coke having domain structure, are expensive and have poor processability. Thus, if it becomes possible to prepare highly graphitized carbons from cheap and processable NGC precursors, the application area should be expanded. For example, although it is hard to form a film of mesophase pitch, cheap films made of polyvinyl chloride (PVC) and chlorinated polyvinyl chloride (CPVC), which are typical NGCs, are easily available. Using such PVC and CPVC films, it would be possible to prepare graphitic thin film with high thermal conductivity, which could be used as a heat release part of IT circuits.

In this study, we tried the conversion of the domain structure of a carbonized spherical phenol resin (one of typical NGC materials) into the GC domain structure through the potassium hydroxide $(\mathrm{KOH})$ treatment. After the graphitization at $2800^{\circ} \mathrm{C}$, the electric conductivity of the graphitized domain-modified sample was evaluated.

\section{Experimental}

A spherical phenol resin (BEAPS series, Asahi Yukizai Corporation, Japan) carbonized at $600^{\circ} \mathrm{C}$ for $1 \mathrm{~h}$ in a flow of $\mathrm{N}_{2}$, was used as a starting material (C6). To modify the domain structure, C6 was heat-treated with KOH (purity > 97.0\%; Wako Pure Chemical Industries,
Ltd., Japan) at $900^{\circ} \mathrm{C}$ for $1 \mathrm{~h}$ using a ramping rate of $5^{\circ} \mathrm{C}$ $\mathrm{min}^{-1}$ in $\mathrm{N}_{2}$ flow $\left(100 \mathrm{~mL} \mathrm{~min}^{-1}\right)$. The weight ratio of $\mathrm{KOH} / \mathrm{C} 6$ was set to 6 . After the heat treatment with $\mathrm{KOH}$, the remaining $\mathrm{KOH}$ and its decomposed species were washed away with $10 \%$ hydrochloric acid aqueous solution and deionized water until the wash water became at $\mathrm{pH} \approx 7$. After the washing, the collected sample was dried at $100^{\circ} \mathrm{C}$ for $3 \mathrm{~h}$ in an air oven and dried again at $150^{\circ} \mathrm{C}$ for $12 \mathrm{~h}$ in a vacuum oven. Thus obtained sample was named as C6K9. Then, C6 and C6K9 were further heat-treated at $2800^{\circ} \mathrm{C}$ for $10 \mathrm{~min}$ under an Ar atmosphere in a horizontal tubular-type graphitization furnace (Kurata Giken Co., Ltd., Japan).

Morphology of samples was observed using a scanning electron microscope (SEM, JSM-6700F, JEOL, Japan). To observe changes in the microdomains, scanning tunneling microscopy (STM) observation of the prepared samples was carried out after heat treatment at $600^{\circ} \mathrm{C}$ under a $\mathrm{H}_{2}$ :Ar (1:4) atmosphere, to remove noise originated from heteroatoms. The STM images were acquired in constant current mode (current range: 0.1-1.0 nA; bias voltage: $0.1-2.0 \mathrm{~V}$; scan frequency: 1-2 Hz) using an Agilent Technologies 5500 Scanning Probe Microscope (Toyo Corporation, Japan). XRD analyses were performed using a RINT 2200 diffractometer (Rigaku, Japan) with $\mathrm{Cu}-\mathrm{K} \alpha$ radiation (wavelength, $\lambda=$ $0.15406 \mathrm{~nm}$ ), generated at $40 \mathrm{kV}$ and $30 \mathrm{~mA}$. Scans were performed at $1.0^{\circ} \mathrm{min}^{-1}$ for $2 \theta$ values between $10^{\circ}$ and $90^{\circ}$. Crystallographic parameters $\left(L_{\mathrm{c}}(002)\right.$, and $\left.L_{\mathrm{a}}(110)\right)$ were calculated using the Bragg and Scherrer equations ${ }^{13,14)}$. Raman spectra were obtained with a Raman spectrometer (NRS-3000, JASCO, Japan) using a 532-nm Ar-ion laser as an excitation source. The first-order Raman spectra of samples were deconvoluted using four disordered (D1, D2, D3, and D4) bands and one ordered $(\mathrm{G})$ band combination ${ }^{15)}$.

Electric resistance, $R$, was measured for sheet type samples by using a digital multimeter (CMD-2000d, Custom. Taiwan). To prepare the sheet type sample, a mixture of the prepared carbon material (95 wt.\%) and

Table 1: Specific electric resistance $(\rho)$, sizes of microdomain and domain, X-ray diffraction crystalline parameters $\left(L_{\mathrm{c}}(002)\right.$ and $\left.L_{\mathrm{a}}(110)\right)$, relative intensity of D1 band to that of $\mathrm{G}$ band $\left(I_{\mathrm{D}} / I_{\mathrm{G}}\right)$, and full width at half maximum intensity of $\mathrm{G}$ band (G-FWHM) in the first-order Raman spectra of C6, C6K9, and their heat-treated samples (C6-H2800 and C6K9-H2800, respectively).

\begin{tabular}{|c|c|c|c|c|c|c|c|}
\hline \multirow[b]{2}{*}{ Sample } & \multirow{2}{*}{$\begin{array}{c}\text { Specific } \\
\text { electric } \\
\text { resistance, } \\
\rho \\
{[\Omega \mathrm{cm}]} \\
\end{array}$} & \multicolumn{2}{|c|}{ STM } & \multicolumn{2}{|c|}{ XRD } & \multicolumn{2}{|c|}{ Raman } \\
\hline & & $\begin{array}{c}\text { Microdomain } \\
\text { size } \\
{[\mathrm{nm}]}\end{array}$ & $\begin{array}{l}\text { Domain } \\
\text { size } \\
{[\mathrm{nm}]}\end{array}$ & $\begin{array}{c}L_{\mathrm{c}}(002) \\
{[\mathrm{nm}]}\end{array}$ & $\begin{array}{c}L_{\mathrm{a}}(110) \\
{[\mathrm{nm}]}\end{array}$ & $\begin{array}{c}I_{\mathrm{D}} / I_{\mathrm{G}} \\
{[-]}\end{array}$ & $\begin{array}{c}\text { G-FWHM } \\
{\left[\mathrm{cm}^{-1}\right]}\end{array}$ \\
\hline C6 & $115.2 \pm 7.3$ & $2-5$ & $2-13$ & $\begin{array}{c}\text { Not } \\
\text { measurable }\end{array}$ & $\begin{array}{c}\text { Not } \\
\text { measurable }\end{array}$ & 1.09 & 61.7 \\
\hline C6K9 & $46.3 \pm 5.8$ & $2-5$ & $2-13$ & $\begin{array}{c}\text { Not } \\
\text { measurable }\end{array}$ & $\begin{array}{c}\text { Not } \\
\text { measurable }\end{array}$ & 1.04 & 112.0 \\
\hline C6-H2800 & $21.9 \pm 1.0$ & $2-10$ & 5-18 & 4.7 & 16.9 & 0.99 & 43.2 \\
\hline C6K9-H2800 & $8.5 \pm 1.0$ & $>25 \mathrm{~nm}$ & $>25 \mathrm{~nm}$ & 20.3 & 22.7 & 0.46 & 27.4 \\
\hline
\end{tabular}


polytetrafluoroethylene as a binder (5 wt.\%) was pressed at $15 \mathrm{MPa}$. Specific electric resistance, $\rho$, was calculated by an equation of $\rho=R A / t$, where $A$ and $t$ are area and thickness of the sample sheet, respectively.

\section{Results and Discussion}

$\rho$ values of starting material (C6), the $\mathrm{KOH}$-treated carbon (C6K9), and their graphitized samples at $2800^{\circ} \mathrm{C}$ (C6-H2800 and C6K9-H2800, respectively) are tabulated in Table 1. C6 with non-graphitizable characteristics showed relatively high $\rho$ value of $115.2 \Omega \mathrm{cm}$. After the graphitization at $2800^{\circ} \mathrm{C}$, it decreased to $21.9 \Omega \mathrm{cm}$ due to the arrangement of a part of the structure by the high
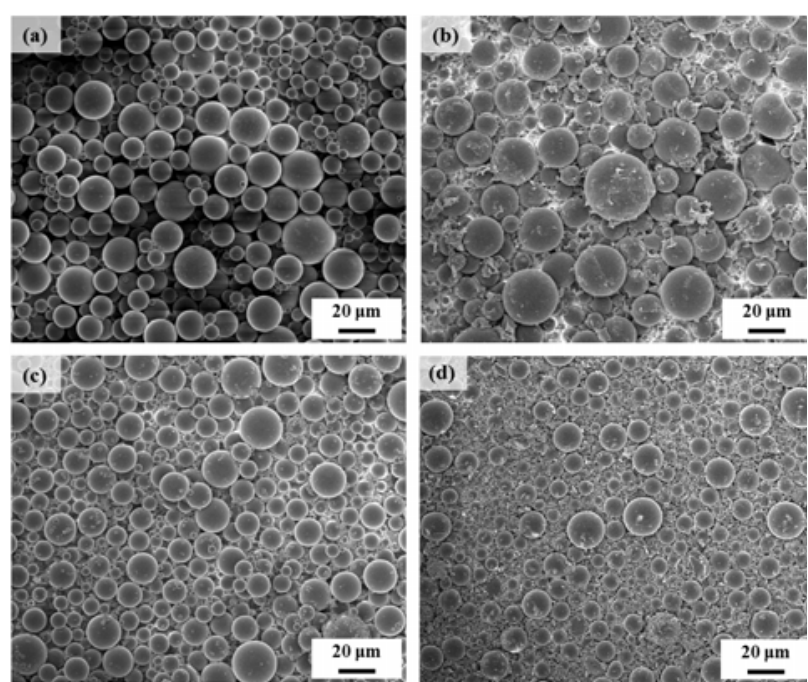

Fig. 1: Scanning electron microscopy (SEM) images of (a) C6, (b) C6K9, (c) C6-H2800, and (d) C6K9-H2800.
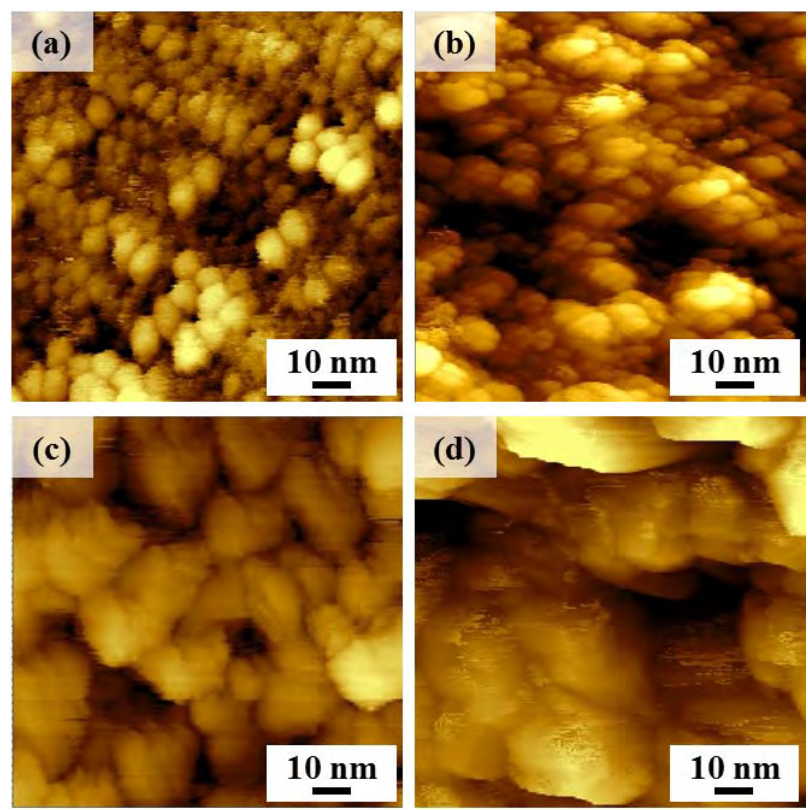

Fig. 2: Scanning tunneling microscopy (STM) images of (a) C6, (b) C6K9, (c) C6-H2800, and (d) C6K9-H2800. temperature treatment. On the other hand, $\mathrm{KOH}$-treated sample (C6K9) showed specific electric resistance of $46.3 \Omega \mathrm{cm}$, which was much lower than the starting material (C6). After the heat-treatment at $2800^{\circ} \mathrm{C}$, C6K9-H2800 showed much less than half $\rho$ value of C6-H2800 $(8.5 \Omega \mathrm{cm})$, suggesting that non-graphitizable structure of C6 was changed into graphitizable one by the $\mathrm{KOH}$ treatment.

In Fig. 1, micrometer-scale morphological images of C6 and C6K9 together with their graphitized samples obtained using SEM are shown. Spherical shape with smooth surfaces of C6 was observed. Graphitization of C6 did not induce detectable changes in shape and size (C6-H2800). In case of the KOH-treated sample (C6K9), on the other hand, the surface became somewhat rough with maintaining the original spherical shape. After the graphitization, the morphology remained unchanged (C6K9-H2800 vs. C6K9).

Since the micrometer-scale morphology was almost unchanged by the $\mathrm{KOH}$ treatment except for the surface roughness as found in Fig. 1, the transformation from non-graphitizable to graphitizable by the $\mathrm{KOH}$ treatment would be induced by a change of nanometer-scale structures. To investigate nanometer-scale morphology, such as microdomain and domain structures, STM was applied. As shown in Fig. 2, C6 showed independent spherical microdomains of $2-5 \mathrm{~nm}$ in diameter. After the graphitization, C6-H2800 showed slightly larger domains (5-18 nm) because a part of microdomains was co-shared with others. The observed microdomain and domain structures of C6 and C6-H2800 were typical for NGC. Contact resistance at boundaries of independent microdomains and domains was considered to interfere the movement of electrons, giving rise to high $\rho$ values for C6 and C6-H2800. For C6K9, the KOH-treated sample, any noticeable changes in size and shape of microdomains were not observed as reported previously ${ }^{16)}$. After the $2800^{\circ} \mathrm{C}$-heat-treatment, however, the coalescence of microdomains became more apparent: Large numbers of microdomains were merged with each other to form large domains. In addition, the boundaries between the domains become more blurred. That is, the $\mathrm{KOH}$ treatment at $900^{\circ} \mathrm{C}$ converted NGC into GC through breaking-down of boundaries of NGC microdomains, which enabled the merging to form modified domains. In Table 1, microdomain and domain sizes estimated from the STM observation are also summarized. 


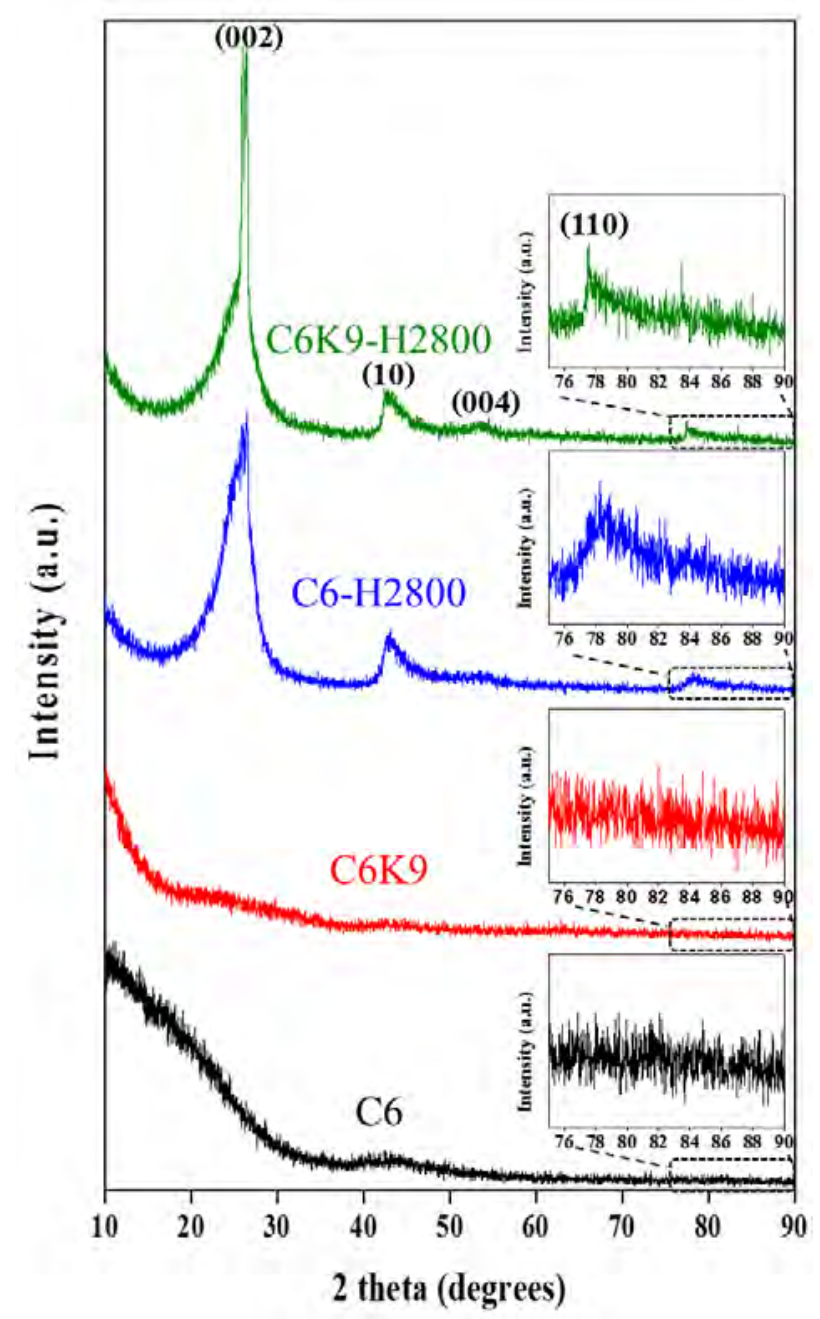

Fig. 3: X-ray diffraction (XRD) patterns of C6, C6K9, C6-H2800 and C6K9-H2800.

To increase the electric conductivity of carbon materials, degree of graphitization and quantity and type of defects are important factors, which can be estimated from XRD and Raman spectroscopy results. Fig. 3 shows XRD profiles of C6, C6K9, and their graphitized samples. C6 showed very obscure peaks of (002), (10), and (110) diffractions, indicating the undeveloped carbon structure. After the graphitization of C6 at $2800^{\circ} \mathrm{C}$, much clearer peaks were observed, whilst the peak broadness indicated the low degree of graphitization (C6-H2800). By the $\mathrm{KOH}$-treatment of $\mathrm{C} 6$, a broad peak at $2 \theta=$ 15-30 was disappeared (C6K9). After the heat-treatment at $2800^{\circ} \mathrm{C}$, C6K9-H2800 showed well-developed and distinct peaks, indicating an increase of the graphitization degree. As shown in Table 1, $L_{\mathrm{c}}(002)$ and $L_{\mathrm{a}}(110)$ values of C6-H2800 and C6K9-H2800 were well-matched with the domain size estimated from the STM observation, suggesting that the graphitic structure was developed the whole length of each domain. In other words, size of domains (a nanometer-scale structure) of carbon materials governed the electronic conductivity (a macroscopic property).

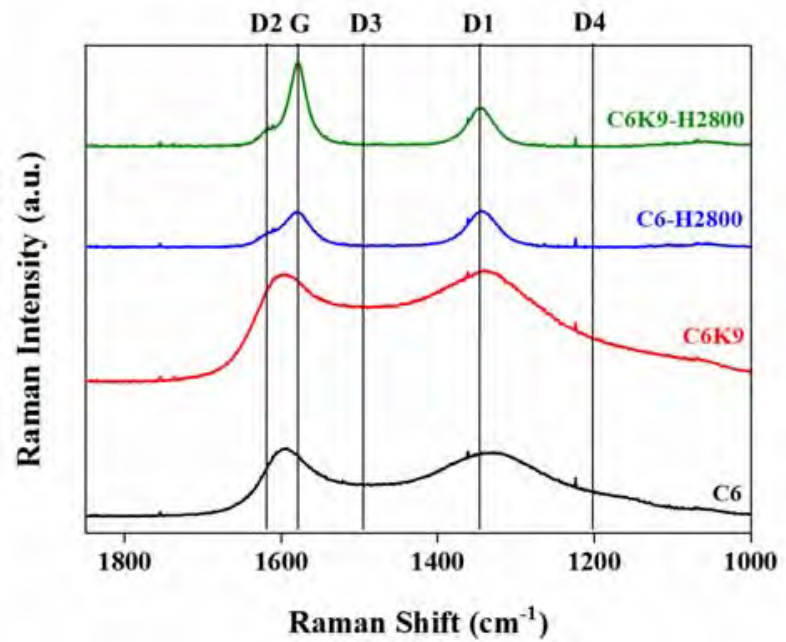

Fig. 4: Raman spectra of C6, C6K9, C6-H2800 and C6K9-H2800.

Fig. 4 shows Raman spectra of C6, C6K9, C6-H2800, and C6K9-H2800. Peaks at 1200 (D4), 1500 (D3), and $\sim 1620 \mathrm{~cm}^{-1}$ (D2) were attributed to $\mathrm{sp}^{3}$ carbon or impurities, amorphous carbon, and disordered carbon, respectively ${ }^{15}$ ). The strong D1 (disorder) band at 1350 $\mathrm{cm}^{-1}$ and other disordered peaks of C6, typical characteristics of NGC, persisted even after the graphitization at $2800^{\circ} \mathrm{C}(\mathrm{C} 6-\mathrm{H} 2800)$. In the case of C6K9, similar spectrum with C6 was observed. For C6K9-H2800, however, most of disorder peaks were remarkably weakened or disappeared. Relative intensities of the $\mathrm{D} 1$ band to that of the $\mathrm{G}$ band, $I_{\mathrm{D}} / I_{\mathrm{G}}$, and full-width at half-maximum of G band ,G-FWHM ${ }^{17)}$, which can be used as indices of the degree of graphitization, are also tabulated in Table 1 . C6K9-H2800 showed the G-FWHM value of $27.4 \mathrm{~cm}^{-1}$, which was much lower than that of C6-H2800 (43.2 $\mathrm{cm}^{-1}$ ). In addition, low $I_{\mathrm{D}} / I_{\mathrm{G}}$ ratio of 0.46 was obtained for C6K9-H2800, again indicating that non-graphitizable feature of C6 was turned into a graphitizable one by the $\mathrm{KOH}$ treatment. From XRD and Raman spectroscopy results, it was confirmed that the non-graphitizable C6 was converted graphitizable carbon by the $\mathrm{KOH}$ treatment, giving rise to the remarkable lowering of electric resistance of C6K9-H2800.

\section{Conclusion}

Graphitizable carbon (GC) was prepared via breaking-down of boundaries of microdomains from non-graphitizable carbon (NGC) using potassium hydroxide $(\mathrm{KOH})$. The structural changes of microdomains and domains in prepared GC were confirmed using XRD, Raman spectroscopy, and STM. In addition, after the graphitization at $2800^{\circ} \mathrm{C}$, graphitized $\mathrm{KOH}$-treated sample showed much less than half (about 39\%) electric resistance value of graphitized NGC, indicating that non-graphitizable structure was successfully changed into graphitizable one by the $\mathrm{KOH}$ 
treatment. The findings in this study pointed out an importance of controlling the nanometer-scale microdomain and domain structures of carbon materials, to improve macroscopic properties, such as electric conductivity.

\section{Acknowledgements}

This research was financially supported by the Ministry of Trade, Industry and Energy (MOTIE) and the Korea Institute for Advancement of Technology (KIAT) through the International Cooperative R\&D program.

\section{References}

1) D.D.L. Chung, J. Mater. Sci., 39, 2645 (2004).

2) R.E. Franklin, Proc. R. Soc. Lond. A, 209, 196 (1951).

3) R.E. Franklin, Acta. Crystallogr., 4, 253 (1951).

4) M. Inagaki, F. Kang, Carbon Materials Science and Engineering: From Fundamentals to Applications, Tsinghua University Press, Beijing (2006).

5) J.D. Bernal, Proc. R. Soc. Lond. A, 106, 749 (1924).

6) O. Hassel, H.Z. Mark, Z. Phys., 25, 317 (1924).

7) B.E. Warren, J. Chem. Phys., 2, 551 (1934).

8) H. Lipson, A.R. Stokes, Nature, 149, 328 (1942).

9) H. Lipson, A.R. Stokes, Proc. R. Soc. Lond. A, 181, 101 (1942).

10)G.E. Bacon, Acta Cryst., 3, 137 (1950).

11)S.H. Yoon, Y. Korai, I. Mochida, Carbon, 34, 83 (1996).

12)I. Mochida, S.H. Yoon, S.Y. Lim, S.H. Hong, Tanso (in Japanese), 215, 274 (2004).

13)F.C. Tai, C. Wei, S.H. Chang, W.S. Chen, J. Raman Spectrosc., 41, 933 (2010).

14)A.K. Kercher, D.C. Nagle, Carbon, 41, 15 (2003).

15)A. Sadezky, H. Muckenhuder, H. Grothe, R. Niessner, U. Pöschl. Carbon, 43, 1731 (2005).

16)D.W. Kim, H.S. Kil, K. Nakabayashi, S.H. Yoon, J. Miyawaki, Carbon, 114, 98 (2017).

17)A. Yoshida, Y. Kaburagi, Y. Hishiyama, Tanso (in Japanese), 221, 2 (2006). 